\title{
EL FRACASO ESCOLAR EN PRIMER CICLO DE LA EDUACIÓN GENERAL BÁSICA COSTARRICENSE. ÁREA LECTOESCRITURA
}

\author{
FAILURE IN READING AND WRITING IN COSTA RICAN ELEMENTARY SCHOOL \\ (FIRST, SECOND, AND THIRD GRADE)**
}

Marielos Murillo Rojas*

\begin{abstract}
RESUMEN
La presente investigación pretende identificar las causas del fracaso y del éxito escolar, a partir del acercamiento de los contextos escolares con elevados índices de fracaso y su contraparte, escuelas exitosas académicamente. En esta primera entrega se presentan únicamente los aportes de las escuelas con rezago educativo y se adiciona un cuadro resumen de las principales causas de fracaso escolar en lectura y escritura, a partir del aporte de sesenta y siete profesionales de la educación.

Palabras clave: Lingüística educativa, educación primaria, fracaso escolar, lectura y escritura.
\end{abstract}

\begin{abstract}
This research "School failure in lower primary education in Costa Rica. Literacy area", aims to identify the causes of failure and success in school, approach from school contexts with high failure rates and their counterparts academically successful schools. In this article is presented only schools with educational backwardness and adding a summary table of the main causes of school failure in reading and writing, from the contribution of sixty seven education professionals.

Key Words: Educational linguistics, primary school, school failure, reading and writing.
\end{abstract}

* Universidad de Costa Rica.

** Traducción: Licda. Geannette Soto. Escuela de Lenguas Modernas, Universidad de Costa Rica.

Correo electrónico: marielosmuro@gmail.com

Recepción: 24/04/13. Aceptación: 31/05/13. 


\section{Introducción}

El presente artículo forma parte de una investigación mayor cuyo objetivo es presentar las causas del fracaso escolar en el área de lectoescritura en el primer ciclo de la educación costarricense, a partir del aporte de un grupo de profesionales que laboran en escuelas con altos índices de rezago educativo y otros en escuelas consideradas exitosas, ambas del sector público. El trabajo que se enmarcó en el proyecto FES/ EDUCACIÓN 2011-2013, el cual pretendía conocer las pautas pedagógicas e institucionales que inciden directamente en el fracaso escolar en primer ciclo de la Educación Básica en el área de lectoescritura.

El sistema educativo costarricense presenta, tal como lo señala el III Informe del Estado de la Educación (2011), fracturas considerables: "en la educación primaria los mayores problemas se concentran en el primer grado, donde el fracaso escolar en el año 2009 fue cercano al $15 \%$, si se suman los casos de exclusión, repitencia y extraedad" (p.130).

Esta situación refleja un sistema educativo con fallas y con dificultades para dar respuestas sociales a los niños y sus familias. El alumno que repite nuevamente el mismo programa vuelve a recorrer el camino ya recorrido, sin adecuaciones, pues no se considera en la actualidad ningún tipo de reajuste programático, el cual, si se diera, beneficiaría el proceso de aprendizaje del escolar.

Aunado a lo anterior, las estadísticas con que se cuenta ocultan las realidades específicas de nuestras aulas, tal como lo señala León (2011); no se sabe qué pasa con los niños que repiten primer grado por segunda vez y por qué en algunas escuelas se encuentran niños con 10 y 11 años en primero y segundo grado; se ignora lo que está sucediendo realmente en las escuelas.

Con el propósito de dar contenido a las estadísticas y responder a estas y otras interrogantes se trabajó con docentes, directores de escuelas, equipos de apoyo y especialistas en lectura y escritura, quienes con su experiencia y conocimientos permitieron identificar las principales causas del fracaso en lectura y escritura, definir el perfil del niño que fracasa, caracterizar al docente que se requiere en primer ciclo, puntualizar las prioridades educativas en el área de lengua, señalar las mejores prácticas pedagógicas, redefinir las competencias de preescolar y primer grado en la enseñanza de la lectura y la escritura, y, finalmente, ofrecer recomendaciones conducentes a reorientar las metas educativas del primer ciclo escolar, específicamente en el área de lenguaje.

Por otra parte, esta investigación y la realizada por León (2010) sobre el fracaso escolar en primer grado, constituyen los primeros aportes específicos sobre esta temática. Aparte de estos estudios, la información de que dispone el Sistema Educativo Costarricense se concreta al conocimiento de estadísticas relativas a cobertura, índices de aprobación, reprobación, deserción, sobreedad, etc. que evidencian aspectos relativos al rendimiento escolar valorado mediante datos estadísticos, pero todavía no se ha develado aún qué hay detrás de esos porcentajes, cuáles son realmente las causas que originan el fracaso, a fin de erradicarlas.

Por tanto, se entrevistó a educadores en servicio, directores de escuela y equipo de apoyo educativo, especialistas en lectura y escritura; estos profesionales contribuyeron a definir el perfil del niño que fracasa en lectura y escritura, determinar las causas de esa problemática y proponer posibles soluciones aplicables en las escuelas costarricenses. Por otra parte, se puntualizan las características de las instituciones exitosas, las cuales podrían ser modelos por replicar, en la medida que los contextos específicos lo permitan.

Ahora bien, para efectos de esta primera entrega y por razones de espacio, se presentan únicamente los aportes de las escuelas con rezago educativo, o sea aquellas con elevados porcentajes de fracaso escolar, y se adiciona un cuadro resumen con las principales causas del fracaso en lectura y escritura, las recomendaciones ofrecidas por los participantes y las estrategias por seguir, para enumerar esos 
abollados senderos de la enseñanza-aprendizaje de la lectoescritura.

\section{El fracaso escolar en la escuela primaria}

La UNESCO, la UNICEF, la OEA, universidades e instancias gubernamentales y privadas en diferentes países, han asumido el reto de investigar y estudiar el fracaso escolar con el propósito de puntualizar sus causas y proponer soluciones a corto, mediano y largo plazo.

En el transcurso del tiempo el concepto de fracaso escolar ha evolucionado, diversos investigadores se han ocupado de hallar una definición más exacta y concreta. Sin embargo, autores como Choque (2009), destacan la dificultad de definir y delimitar la problemática de fracaso escolar, debido a que "el resultado de la educación no sólo depende de la institución educativa, sino de estudiantes, familias, profesores, comunidad, vecindario, medios de comunicación, políticas de estado y de la sociedad con sus diferentes organizaciones" (Choque, 2009:1) Asimismo, este autor señala que las aspiraciones de un sistema educativo en torno al éxito escolar y los requisitos que se establezcan para avanzar en el sistema, también determina la conceptualización del fracaso escolar.

En América Latina se han realizado propuestas para mitigaresta problemática, paralo cual se ha profundizado en la conceptualización y en la definición de las causas del fracaso escolar. Según Fernig (1972), a pesar de que el derecho a la educación fue incorporado en la Declaración Universal de Derechos Humanos, aprobada por las Naciones Unidas en 1948, existen grupos minoritarios que desde el inicio de un curso lectivo presentan grandes desventajas (minorías étnicas, estudiantes de zonas rurales, niños provenientes de contextos socioeconómicos bajos) y deben enfrentar obstáculos que muchas veces no son superados, situación que desencadena en fracaso escolar (Passow, 1972).
Este fenómeno ha sido analizado desde diferentes perspectivas, según el momento histórico y enfoques teórico-metodológicos que han sustentado esos estudios. En términos generales, las causas del fracaso escolar en lectoescritura se han atribuido a factores externos, personales e internos.

Los primeros están representados por la familia, la disparidad lingüística, factores geográficos y grupos de población desfavorecidos. La familia tiene una influencia decisiva en el desarrollo psicobiológico y capacidad intelectual del niño; por tanto, el clima afectivo de las relaciones internas, así como el nivel cultural y económico familiares determinan poderosamente la receptividad y la adaptación del alumno en su proceso de escolarización. La disparidad lingüística se refiere a la enseñanza impartida en una lengua que no es la materna y sus consecuencias en los procesos de comprensión. La zona rural presenta varias desventajas, por ejemplo, la poca cobertura, horarios reducidos, carencia de recursos didácticos, maestros menos calificados o carentes de título.

Respecto de la segunda causa, el factor personal, se critica la estructura de la organización vigente que agrupa a los alumnos por grado y en programas, con la pretensión de homogenizar a los escolares, lo que influye en el papel docente y su accionar colectivo. Ese accionar no considera las diferencias individuales y concentra su atención en un resultado por aprobar, obviando los ritmos individuales de aprendizaje. Además, se establece la relación entre la afectividad y los resultados escolares, pues en la medida que se suscite el interés del alumno por la vida y las tareas escolares los resultados serán mejores. Otro aspecto valorado son las "insuficiencias personales", o sea aquellas determinadas por las dificultades en el aprendizaje escolar: nutrición, problemas de tipo orgánico, sensoriales, neurológicas u otras de tipo específico para el aprendizaje, como la dislexia, la discalculia y otras dificultades.

Las causas internas, como factor del fracaso escolar, se centran en el sistema educativo y su funcionamiento, por ejemplo se señala la 
cobertura, falta de incentivo a los docentes, programas de estudio, nivel de calificación de los docentes, calendarios y horarios.

Blat (1984) considera que estos factores interactúan y que, por tanto, "las circunstancias determinantes del fracaso escolar varían mucho de un lugar a otro y que los resultados escolares pueden mejorar significativamente mediante una acción educativa eficaz" (Blat, 1984:53).

La pluralidad de miradas y la priorización de un factor sobre otro a lo largo del tiempo, ha orientado las políticas gubernamentales hacia aspectos específicos, sin considerar el fenómeno desde una óptica integral y diferenciada entre un niño y otro.

En el año 2002, López, N. y Gluz, N., analizan este problema mediante estrategias sistémicas que atiendan la deserción, la repitencia y la sobreedad. Se señala que está ampliamente documentado que las condiciones materiales de vida y las características socioculturales de las familias determinan en gran medida el desarrollo de actitudes y expectativas que no siempre favorecen al éxito escolar de los niños. Adicionalmente al nivel sociocultural de los alumnos y sus familias, se suma el tipo de organización escolar y de prácticas pedagógicas, los cuales en su conjunto consolidan las probabilidades diferenciales de éxito, conformando un circuito causal que se refuerza constantemente.

Farías, M., Fiol, D., Kit, I. y Melgar, S. (2007), centran su interés en las propuestas para superar el fracaso escolar y resaltan su huella negativa en la experiencia educativa del niño. "El fracaso perjudica la consolidación de la autoestima y reduce la confianza en su capacidad para enfrentar situaciones desafiantes. Por otro lado, la repitencia en los primeros años predice el doble de probabilidades de abandonar la escuela secundaria sin completarla. Estos costos son desiguales, pues afectan mayoritariamente a los niños y niñas más pobres..." (Acosta, 2007:7).

La repitencia como evidencia del fracaso:

(...) afecta a los primeros grados de la escuela primaria y, de modo especial, al primer grado, punto de entrada al sistema, en el que se constituyen los fundamentos y los aprendizajes esenciales que condicionarán, positiva o negativamente, los futuros aprendizajes, la autoestima y la autoconfianza. La repetición en los primeros grados está estrechamente vinculada a problemas en la enseñanza de la lectura y la escritura, basada en comprensiones estrechas y atrasadas del lenguaje y de los procesos de aprendizaje infantil, y atada a viejos métodos pedagógicos. Por lo demás, estudios en diversos países confirman que la alfabetización y el área Lenguaje en general, ocupan un lugar central en la decisión docente de promover o hacer repetir el año a un alumno (Torres, 2007: 26).

Por otra parte, la mayoría de estudios realizados en países desarrollados confirma que la repitencia en vez de asegurar el aprendizaje, es el primer paso hacia la deserción escolar.

Para Torres (2007) es evidente que los motivos que llevan a un estudiante a repetir un año son variados, pero el más común se circunscribe a las calificaciones insuficientes para ser promovido. Unido a esta circunstancia están las premisas pedagógicas equivocadas sobre la repetición:

- $\quad$ El estudiante que no aprendió lo suficiente en un nivel escolar, aprenderá más si recorre dos veces (o más) el camino.

- Como no se aprendió nada en el año escolar, vale la pena iniciar de nuevo.

- El conocimiento y el aprendizaje son resultado de la ejercitación repetitiva.

Esas premisas educativas se unen a otras variables que afectan el desarrollo personal, social, afectivo y, por tanto, la conducta del alumno.

En el área social, la repetición se convierte en un reforzador del círculo vicioso de bajas expectativas (bajo rendimiento, baja autoestima y fracaso escolar), al mismo tiempo, los padres de familia visualizan la situación como una señal de la incapacidad de aprender que tienen sus hijos. En el área administrativa y financiera, la repetición se traduce en un enorme desperdicio de recursos y se dice que indirectamente es causal de ineficiencia escolar, esto porque los recursos se destinan a cubrir la demanda de los repitentes y no en la cobertura de otras necesidades. 
Al analizar la repitencia por niveles, en el primer año de escolarización, las causas más relacionadas con ésta son problemas en el lenguaje oral y escrito, a pesar de que los especialistas en alfabetización "no establecen de manera taxativa y universal qué nivel de dominio debe manifestar el alumno o la alumna al final del primer año; sí consideran que la alfabetización inicial se cumple en un plazo variable de por lo menos dos años completos." (Torres, 2007:32). A partir de segundo y tercer año, se menciona que se debe a ciertas debilidades o aprendizajes fallidos en el área de Matemáticas.

Por otra parte, Choque (2009: 1) manifiesta que "el resultado de la educación no solo depende de la institución educativa, sino de estudiantes, familias, profesores, comunidad, vecindario, medios de comunicación, políticas de estado y de la sociedad con sus diferentes organizaciones". Es por esto imposible circunscribir el fracaso escolar a una única causa, ya que está determinado por un sinfín de variables.

Quizá el problema más serio ha sido el establecimiento de una correspondencia biunívoca entre fracaso escolar y calificaciones insuficientes, aspecto que irremediablemente centraliza esta problemática en la figura del niño, pero, ¿qué pasa si la mirada se vuelve hacia quien enseña, o sea el maestro y sus estrategias metodológicas, por ejemplo?

También se ha fijado la mirada hacia la educación preescolar y su baja cobertura en Latinoamérica, pero; ¿qué pasa cuando los porcentajes de reprobación en primer grado se mantienen, pese a una amplia cobertura en este nivel?

Por otra parte, Blat (1984) destaca que el fracaso escolar tiende a ser confundido con el fracaso del escolar, perspectiva que visualiza al estudiante como el único culpable por no haber cumplido con los requisitos de la escuela para avanzar al siguiente nivel. Este autor llama la atención sobre otras variables que intervienen en el fracaso escolar y destaca que esta problemática no es sinónimo de reprobar un ciclo lectivo ni de mantener un promedio bajo en las calificaciones; el fracaso escolar tiene más indicadores como el ausentismo total de la escuela, el abandono prematuro de ésta, la repetición de cursos y la relación entre el número de años de asistencia a la escuela y la duración normal de los estudios primarios.

Binstock y Cerutti (2005) le prestan atención al abandono escolar y lo visualizan como uno de los indicadores de fracaso escolar, además se menciona que es un proceso complejo y cambiante que "se desarrolla a lo largo del tiempo y en el que confluyen factores sociales, económicos, familiares, cognitivos e institucionales experimentados durante la vida de los adolescentes" (Binstock y Cerutti, 2005:11).

En Costa Rica, León (2010) analiza las principales razones del fracaso escolar en primer grado y señala que este fenómeno educativo se da básicamente en las transiciones de ciclo, o sea, de preescolar a primer grado, de sexto grado a sétimo año y de undécimo año a la educación superior universitaria. Estas transiciones son críticas debido a los cambios de logística -funcionamiento y requerimientos de cada ciclo en particular- y a los conflictos relacionados con el incumplimiento de metas propias de los niveles anteriores.

Como aspectos medulares de la investigación de León (2010) se rescata el abordaje del fracaso escolar más allá del desempeño académico, formalidad o exigencia para trascender a la cultura de aprender a aprender, pues el hecho de "pasar" de nivel no significa que se dé un proceso de aprendizaje. Igualmente se resalta el papel homogenizador de la evaluación vista como una calificación que induce a aprender para ser evaluado. Unido a lo anterior los principales obstáculos en primer grado serían "el excesivo número de alumnos y alumnas por docente, las dificultades con el dominio lingüístico, la falta de docentes capacitados para impartir ese nivel y la ausencia de material pedagógico adecuado" (León, 2010: 15).

Profundizando en el niño y sus procesos de aprendizaje esta autora considera que las exigencias y logros esperados para los niños 
de primer grado, son muy similares a los del nivel subsiguiente, por lo que la presión para los infantes es mayor. "Este factor también puede contribuir a incrementar el fracaso, al demandar de los y las estudiantes destrezas o habilidades para las cuales aún no están listos" (León, 2010:17).

En este orden se presentan recomendaciones estratégicas para disminuir el fracaso escolar, a partir de la lectura que hace León (2010) de Casanovas (2007), Fernández (2003), NAEYC (2010), Sink y Edwards (2007), UNESCO (2007), Copple y Bredekamp (2009):

- Modificación de la práctica pedagógica, capacitación de los docentes y fortalecimiento de la enseñanza de la lengua y matemática, con lo que se sientan las bases para disminuir el riesgo del abandono escolar en lo secundario.

Análisis de la política de promoción, plantear objetivos de aprobación de grado sobre la base del logro de competencias por ciclo, así como una nueva normativa de evaluación de los aprendizajes, que cumpla las funciones de diagnosticar y motivar, y no tanto una función administrativa ni de penalización.

- Repensar las metodologías de trabajo, pues el juego debe ser una herramienta de aprendizaje, la cual está ligada a la cantidad de niños por grupo y el número de docentes encargados. La tarea fundamental será emplear metodologías centradas en el estudiante.

- $\quad$ Establecer modificaciones sustanciales en los criterios de evaluación, en las que la observación será un medio para estimular los nuevos aprendizajes.

- Involucrar a todos los participantes del proceso educativo.

- Articulación y transición positiva entre la educación preescolar y primaria, mediante la aplicación de un plan de estudio integrado para la educación preescolar y primaria, "organizando los ciclos de aprendizaje en función de los ciclos de desarrollo del niño." UNESCO

(2007), citado por León (2010:24).

Por otra parte se enumeran los factores que definen el éxito en primer grado, obtenidos por León (2010) mediante encuestas a docentes costarricenses de primer grado:

- Madurez en el área motora gruesa y fina.

- $\quad$ Estimulación recibida en el lenguaje y en el área cognitiva.

- $\quad$ Estimulación del área social y emocional del infante, de tal manera que el niño sea capaz de establecer relaciones positivas consigo mismo y con sus pares.

Sólida preparación en el nivel preescolar, que involucre todas las áreas del desarrollo.

- Trabajar de manera integral y utilizar metodologías que le permitan al infante adquirir habilidades de lectoescritura.

- Utilizar metodologías que impliquen el elemento lúdico y constructivista, a partir de los aprendizajes previos.

- Fortalecer un ambiente físico y social agradable para el niño.

- Organizar grupos equilibrados entre el número de estudiantes y el número de docentes que les atienden.

- Docentes innovadores y comprometidos con su labor, que además de estimular el área cognitiva, se preocupen por las emociones y el área social de sus estudiantes.

- Trabajar en equipo con las familias, para que éstas apoyen y refuercen las habilidades y los conocimientos abordados en la escuela.

- Todos los actores que intervienen en la educación deben mantenerse motivados y comprometidos con el proceso.

Respecto de esas encuestas, León (2010), en resumen, concluye: "Pueden identificarse de las respuestas, tres conjuntos de factores que se identifican como claves para el éxito 
en primer grado: los que pertenecen al propio individuo y estudiante; los que son de carácter metodológico y los que se refieren a apoyos $y$ trabajo conjunto docente-centro educativofamilia" (León, 2010, p. 40).

A través de las encuestas realizadas a los docentes participantes en el estudio en referencia, la autora identifica aspectos que deben modificarse en preescolar para disminuir el fracaso y la repetición en primer grado:

- Familiarizar a los niños y niñas con la metodología de primaria, también acercarlos a la escuela (llevarlos de visita).

- Utilizar estrategias metodológicas que permitan desarrollar gusto y aprecio por la lectura y escritura, así como otras habilidades necesarias para primer grado.

- Brindar servicios de apoyo que propicien una intervención oportuna, así será más sencillo identificar y abordar los problemas de aprendizaje.

- Promover la estimulación en el área motora fina, ya que en primer grado se requiere de madurez en esta área.

- Involucrar a la familia y propiciar un compromiso con el proceso educativo.

- Que los docentes y los programas estén en función del estudiante.

En cuanto a los cambios necesarios en primer grado para reducir el fracaso escolar, los docentes encuestados por León (2010), enumeraron los siguientes factores:

- Trabajar en el proceso de transición de preescolar a primaria, para que el cambio no sea drástico, sino se alcance un equilibrio entre ambos niveles.

- Utilizar una metodología más flexible, lúdica y concreta, para disminuir las metodologías tan conductistas ya existentes.

- No etiquetar a los estudiantes, sino trabajar en el abordaje de sus problemas.

Trabajar en la parte administrativa y organizativa para ser más eficientes.
Que los docentes cuenten con las cualidades necesarias para atender a los niños y niñas.

- Involucrar a las familias en el proceso educativo.

Según León (2010), es importante utilizar en primaria las estrategias metodológicas empleadas en preescolar, pero ajuntándolas a los contenidos de los grupos de edad que se atiende.

En síntesis, el término fracaso escolar es utilizado para abarcar una serie de fenómenos personales, educativos y sociales, cuyo denominador común es una afectación negativa a la vida del escolar, ya sea por exclusión, por repetición, por problemas de rendimiento o por generar sobreedad. En este contexto fracasa la escuela, fracasa la familia y fracasa el niño, receptor de múltiples variables que intervienen en su proceso formativo.

De acuerdo con la bibliografía consultada las soluciones propuestas en torno a la temática de la repitencia, se caracterizan por ser superficiales y remediales, mientras que lo necesario es que sean preventivas y sistemáticas para sanear el problema desde la raíz.

Ante la evidente necesidad de atender de forma preventiva y sistemática el fracaso escolar como fenómeno de causación múltiple, la tarea corresponde a voces contestatarias y propositivas plurales: políticas educativas que privilegien la continuidad en los procesos educativos, definición de prioridades sociales y educativas, involucramiento de la educación preescolar y la primaria, respuesta eficiente de la institución educativa y, por tanto, de sus maestros, y el oportuno esfuerzo de las familias.

\section{Metodología de trabajo}

La investigación se abordó desde una perspectiva cualitativa y mediante el análisis de contenido de treinta y siete entrevistas realizadas durante los meses de octubre, noviembre y diciembre de 2011, con el propósito de identificar las causas del fracaso escolar en la Educación General Básica Costarricense y las de su contraparte el éxito escolar. 
A continuación se detallan los aspectos fundamentales metodológicos considerados en esta investigación.

\subsection{Causas del fracaso escolar en lectura y escritura en una muestra de escuelas públicas con altos índices de repitencia, deserción y reprobación en primer ciclo de la educación general básica}

De las 20 escuelas con mayores índices de repitencia, deserción y reprobación en primer ciclo escolar costarricense, se tomaron 8 instituciones, elegidas de acuerdo con las posibilidades de desplazamiento de la investigadora principal y su equipo de apoyo. En total se entrevistó a 18 profesionales de la educación primaria que desempeñaba alguno de los siguientes puestos: maestro de primer ciclo, director de la escuela, miembro del PRIN ${ }^{1}$, miembro del equipo interdisciplinario y miembro del servicio de problemas de aprendizaje.

Estas entrevistas fueron diseñadas con preguntas clave para todos los entrevistados y algunas diferenciadas, según la labor profesional de cada uno y su relación con los niños que fracasan en lectura y escritura.

A partir de las preguntas generadoras y las narraciones de los educadores participantes se elaboró una matriz que permitió identificar las causas del fracaso escolar en lectura y escritura y las posibles soluciones evocadas por los mismos entrevistados.

\subsection{Condiciones socioeducativas de escuelas públicas exitosas, o sea aquellas que muestran elevados índices de aprobación en primer ciclo de la educación general básica}

Con el propósito de profundizar en la realidad educativa costarricense se seleccionarán seis escuelas con elevados índices de aprobación en primer ciclo y por la calidad de su trayectoria educativa, valorada en virtud de la información suministrada por el Ministerio de Educación, en las cuales se realizaron trece entrevistas a profundidad a directores y a educadores que impartieron primer ciclo durante el año 2010.

A partir de las preguntas generadoras y las narraciones de los educadores participantes, tal como se procedió en el apartado 3.1., se elaboró una matriz que permitió identificar las variables que favorecen el éxito en lectura y escritura en esas escuelas públicas de Costa Rica.

Además se validaron las variables que definen el éxito o el fracaso escolar mediante el aporte de un grupo focal de 30 docentes de preescolar y primaria, quienes valoraron los resultados obtenidos en los puntos 3.1. y 3.2. de la presente investigación.

Finalmente y con el propósito de establecer un diálogo entre los aportes de los docentes, directores de escuelas, equipos de apoyo y especialistas se entrevistó a seis personas con amplios conocimientos en los procesos de lectoescritura inicial e inmersas en la realidad educativa costarricense. Los temas consultados fueron: predictores de éxito en el aprendizaje de la lectura y la escritura, métodos de lectoescritura inicial, papel de la educación preescolar en el aprendizaje inicial de la lectoescritura, dificultades en el aprendizaje de la lectura y la escritura y recomendaciones para el primer ciclo escolar. A continuación se detallan las características de las personas entrevistadas:

\subsection{Instrumentos}

Las entrevistas tenían como propósito identificar las causas del fracaso escolar en lectura y escritura en primer ciclo de la educación general básica; por tanto, los instrumentos giraron en torno a los siguientes aspectos:

a. Perfil del niño con fracaso escolar: contexto familiar, escolar y características personales.

b. Causas del fracaso escolar: contexto familiar, contexto escolar (la escuela y sus características, la intervención pedagógica, criterios de aprobación 
escolar, objetivos del primer ciclo escolar, planes y programas), desempeño del niño.

c. Respuesta de la escuela ante el fracaso escolar.

d. Características de una escuela exitosa.

e. Respuesta de la escuela exitosa ante las dificultades escolares.

f. Las dificultades específicas en lectura y escritura.

En suma, en la investigación general participaron sesenta y siete informantes, quienes, desde su experiencia y formación profesional, aportaron información fundamental para identificar las causas del fracaso escolar en lectura y escritura en niños de primer ciclo escolar. En el mismo sentido estos profesionales ofrecen recomendaciones dirigidas, fundamentalmente, a la escuela como institución responsable de controlar los aspectos curriculares y pedagógicos que intervienen en el aprendizaje de la lectura y la escritura.

\subsection{Análisis de la información}

\section{El fracaso escolar en lectura y escritura en primer ciclo \\ Las causas del fracaso escolar se} identifican a partir de los aportes ofrecidos por los profesionales entrevistados de las escuelas de rezago educativo. Mediante las entrevistas se obtuvo información general y específica que permitió elaborar el perfil del niño que fracasa en el sistema educativo al analizar las variables: el contexto (familiar, comunal y escolar), el desempeño del escolar y el desempeño del docente. En la siguiente tabla se presentan los principales aportes.

TABLA 1.

Causas del fracaso escolar

\begin{tabular}{ll}
\hline Contexto & \multicolumn{1}{c}{ Indicadores } \\
\hline Contexto familiar & - Desintegración familiar, altos porcentajes de maltrato, abuso emocional y físico. \\
& - Porcentaje elevado de familias disfuncionales: abandono, niños que quedan bajo la \\
& responsabilidad de vecinos, abuelos, tíos, hermanos mayores, etc. \\
& - Niños desatendidos por sus familias, regularmente están en la calle o viendo televisión. \\
& - Familias con problemáticas de drogadicción, de prostitución, y de problemas intrafamiliares. \\
& Las familias "buenas" son las menos. \\
& - Condiciones precarias de vivienda: hacinamiento, cuarterías sin divisiones internas, etc. \\
& - Madres jefas de hogar con baja autoestima, acostumbradas a un sistema de regalías fomentado \\
& por los diferentes gobiernos. \\
& - Problemas sociales como la delincuencia, la desocupación y la indigencia. \\
& - Altos porcentajes de población inmigrante fundamentalmente nicaragüense. \\
& - Padres totalmente ausentes, sin compromiso alguno. \\
& - Espacio físico insuficiente para atender las necesidades de los escolares. \\
& - Escuelas con jornadas diferenciadas (jornada ampliada, jornada regular y tercera jornada). \\
& - Grupos sobrecargados, entre 35 y 40 alumnos. \\
& - Niños con problemas de alimentación. \\
& - Fluctuación de matrícula. \\
& - Niños con hambre completamente abandonados. \\
& - Insuficiente personal especializado para atender a los niños con problemas de conducta y de \\
& aprendizaje. \\
& - En el medio estos niños muestran conductas agresivas, con serios problemas de \\
& comportamiento, pues no tienen reglas ni límites en la casa. \\
& - Falta de acompañamiento familiar; es usual que los niños lleguen solos a la escuela, sin un \\
& adulto responsable que los acompañe. \\
\hline &
\end{tabular}




\begin{tabular}{ll}
\hline Desempeño escolar & - Alto porcentaje de ausentismo, el cual acelera la deserción. \\
& - Incumplimiento con las labores propias del entorno escolar. \\
& - Falta de motivación hacia el estudio y hacia la escuela. \\
& - Estilos de enseñanza que no corresponden a los estilos de aprendizaje de los niños con \\
& dificultades escolares. \\
\hline Apoyo comunal & Las escuelas cuentan con apoyos, en mayor o menor escala, de entes gubernamentales y \\
& privados: municipalidades, asociaciones de desarrollo, instituciones privadas, clínicas del \\
& Seguro Social, EBAIS, etc., pero no son suficientes. \\
\hline Relación familia- & Poco compromiso de los padres, lo cual influye en el proceso de aprendizaje de los niños. \\
escuela & - Dado que no existe una comunicación fluida hogar-escuela se da un alto porcentaje de \\
& ausentismo. \\
& - Usualmente los padres llegan a la Dirección a quejarse por alguna situación o conflicto en \\
& que están involucrados sus hijos. \\
& - Muy poca asistencia a las reuniones convocadas por los maestros o la dirección de la \\
& institución. \\
& - La convocatoria con mayor acogida es la entrega de notas.
\end{tabular}

La tabla anterior muestra una realidad carente de oportunidades, en la que la dinámica familiar se aleja del ideal de la institución escolar, o sea familias funcionales, preocupadas por el desarrollo y bienestar del niño y pendientes de los requerimientos de la escuela. No obstante, el niño, pese a que conviva en un medio familiar disfuncional, tiene el derecho de recibir una educación de calidad, que le permita compensar los déficits ambientales de que ha sido objeto. Por tanto, la institución escolar que conozca la realidad de los niños que alberga, éticamente no puede ni debe justificar el fracaso escolar en virtud del contexto familiar que les correspondió vivir a los niños provenientes de familias ausentes.

Estos niños que, quizá muestren dificultades en su desempeño escolar, deben ser objeto de intervenciones puntuales a fin de minimizar sus déficits ambientales.

Por otra parte, el contexto escolar debe ofrecer una infraestructura $y$ un ambiente mucho más estético que aquel que el escolar está acostumbrado a apreciar. Si el escolar vive en un espacio familiar hacinado y la escuela ofrece condiciones similares, dónde está, entonces, el esfuerzo compensatorio que corresponde a la institución educativa. Por ejemplo, en una de las escuelas de atención prioritaria que participó en esta investigación se señala que: "actualmente se necesitan treinta aulas para I y II ciclo (...) no hay una sala de maestros, los docentes tienen que dar PRIN en el corredor porque no hay espacio. En este mismo orden, las jornadas diferenciadas (ampliada, regular y tercera) son reflejo también de la inequidad vivida en las instituciones educativas, pues las escuelas con tercera jornada ofrecen menos lecciones, situación que resta tiempo a los procesos de educación formal, ya que no es lo mismo recibir tres horas y media diarias de clases a recibir seis."

El ausentismo del escolar, si no es motivado por un cambio de domicilio, se controla mediante la labor de seguimiento del equipo interdisciplinario y la notificación del docente encargado de grupo. Pero, cuando el ausentismo es consecuencia de movimientos migratorios o de expedientes en proceso de estudio por parte del Patronato Nacional de la Infancia la situación se agrava; al respecto la Directora de la Escuela Central de San Sebastián comentó que “ (...) en un mes se pueden dar sesenta y cuatro traslados y al mes siguiente regresan los mismos sesenta y cuatro niños que se habían ido; algunos de esos estudiantes eran víctimas de agresión en sus hogares o estaban viviendo problemas de separación, o bien hijos de padres indocumentados que se van a buscar trabajo a otras zonas" (M.Sc. Jenny Alexandra Prado Marín, comunicación personal, 1 de setiembre 2011). Esos niños abandonan la escuela por un mes y pierden el ritmo del proceso educativo respecto de sus compañeros, por tanto, son candidatos al fracaso escolar. 
El ausentismo prolongado tiene como consecuencia inmediata la reprobación, ya que el escolar no logra nivelarse y, a su vez, engruesa los listados de otro de los males escolares, la sobreedad, muy común a partir de segundo grado.

Ahora bien, la reprobación, el ausentismo, la sobreedad y las dificultades en el aprendizaje, unidos a una dinámica familiar que riñe con los ideales de la institución escolar, se constituyen en variables que irremediablemente afectan el comportamiento del niño, disminuyen su sentido de capacidad $\mathrm{y}$, con frecuencia, se reflejan mediante conductas agresivas que interfieren en los propios procesos de aprendizaje y en la dinámica grupal. Por tanto, la presencia de equipos de apoyo institucional es apremiante.

Unido a lo señalado el contexto escolar no debe desconocer que la motivación, la emoción por aprender, el reto, la curiosidad, el gusto por leer y escribir deben ser también tarea de la escuela; esas condiciones son previas a la introducción de contenidos temáticos aislados, sin las cuales carecerán de sentido y pertinencia. Los estilos de enseñanza también deben ser distintos.

En fin, sostenemos que las causas del fracaso escolar propuestas en la tabla 1, ofrecen un panorama básico para iniciar la discusión sobre los aspectos de la organización escolar (disminución de niños por grupo, supervisión docente, rendición de cuentas, integración curricular, programas compensatorios, etc.), la priorización de competencias por desarrollar, la revisión del rol docente y la asunción de las responsabilidades, según sea el caso.

Por otra parte, tal como lo atestiguan las entrevistas realizadas no existe un programa específico que atienda a los niños repitentes, por lo que estos deben cursar nuevamente todo el programa independientemente de cuáles sean sus dificultades escolares. Por ejemplo, un niño que está repitiendo primer grado, quizá conozca las vocales, algunas sílabas y no requiera del "período de apresto", usual durante los dos primeros meses del año, pero, aunque se aburra, tiene que realizar las mismas actividades que sus compañeros de primer ingreso. En consecuencia, estamos ante una práctica docenteorientada hacia la colectividad, la homogeneidad representada por grupos que avanzan a un mismo ritmo. Pero la realidad es otra, los grupos son heterogéneos, con experiencias previas, sentido de capacidad, motivación hacia el aprendizaje y conocimientos sobre lectura y escritura distintos. Creemos que solamente si se responde oportunamente a esa heterogeneidad la escuela puede llegar a construir estrategias pertinentes para atender las dificultades del aprendizaje de la lectura y la escritura y frenar el fracaso escolar.

En virtud de los datos de la tabla 1, se recomienda que las estrategias pedagógicas para tratar las dificultades en lectura y escritura sean creadas por los mismos maestros, por lo que se considera urgente realizar procesos de inmersión en aulas de grupos especiales de repitentes, aulas regulares con repitentes, observación de la labor de los grupos de apoyo, a fin de dilucidar cuáles serían las estrategias rentables en términos de beneficios académicos y personales para los niños con dificultades de lectura y escritura.

Por otra parte, la rentabilidad del servicio de PRIN, en términos de éxito escolar en lectura y escritura de los niños que han sido beneficiados con ese servicio, se desconoce, pues la ejecución del programa es "irregular", mejor en unas escuelas que en otras. Es aconsejable, por tanto, evaluar esos servicios a fin de definir claramente el perfil del potencial beneficiario, reorientar acertadamente la orientación pedagógica y el énfasis curricular.

En suma, estamos en presencia de una manera de ejercer la labor docente que privilegia la voz de la colectividad en detrimento de la individualidad. La voz que casi no se escucha se pierde en la algarabía del colectivo y reaparece engrosando los porcentajes de la desaprobación escolar.

Si bien la pedagogía es una disciplina con fuertes raíces humanistas, orientada hacia el desarrollo integral del estudiante, ¿por qué la intervención didáctica se mira con el lente de la colectividad? En opinión de los directores encuestados de las instituciones escolares respectivas existe una falla en la organización y planificación del trabajo de aula, inducida 
por la estructuración de programas centrados en el contenido, la presencia de grupos muy numerosos y por carencias en la formación profesional; además de una carga administrativa excesiva que impide al docente maximizar el tiempo lectivo.

En consecuencia, la deserción, el ausentismo y la reprobación evidencian la necesidad de respuestas inmediatas, por ejemplo: dar seguimiento a los repitentes, diagnosticar y atender tempranamente las dificultades escolares, adecuar la programación didáctica, etc.

Criterios fundamentales para reprobar a un niño en primer grado

Los porcentajes de niños repitentes, ausentes y reprobados preocupan a muchos, pero ocupan a pocos. Consideramos que parte de esa ocupación está inicialmente ligada con la identificación de conocimientos, competencias o temáticas necesarias para aprobar primero, segundo y tercer grado. Por consiguiente, se solicitó puntualmente a los participantes que mencionaran los criterios pedagógicos que determinan la aprobación o reprobación del primer grado, ante lo cual se obtuvo como respuesta unánime: la comprobación de que el niño sabe leer y escribir. Lo que no queda claro es qué tanto dominio de estos conocimientos se requiere, pero es recurrente la afirmación de que estos conocimientos son básicos para continuar transitando con éxito por la escuela.

Ahora bien teóricamente se sabe que el aprendizaje de la lectura y escritura se adquiere durante un período mucho más extenso, comprendido en el rango de los cinco a diez años (Ortiz, 2009). Ante esta realidad es urgente definir para el contexto escolar costarricense las competencias lectoras para cada grado del primer ciclo.

Adicionalmente, se justifica la reprobación en virtud de razones externas a la escuela:

- $\quad$ Falta de motivación de los niños causada por problemas familiares, no hay interés hacia la escuela ni por su propio futuro.

- $\quad$ Falta de apoyo en el proceso educativo y compromiso de los padres de familia.
- El ausentismo, lo que provoca que se interrumpa el proceso de aprendizaje.

Al tenor de los puntos señalados, la escuela tiende a mirar hacia fuera, no se autoevalúa, no reflexiona sobre su quehacer cotidiano y las formas para retener a los niños.

Quizá sea necesario encauzar la reflexión escolar hacia la construcción de una escuela autosuficiente, o sea aquella que minimiza la responsabilidad familiar y maximiza su propio compromiso.

Unido a lo señalado se reconocen otros aspectos que impiden el éxito escolar.

- Metodologías tradicionales que conciben al niño como un receptor pasivo de conocimientos, sin valorar los conocimientos previos ni sus características personales.

- $\quad$ Falta de apoyo de las familias al proceso educativo que se lleva en las aulas. La principal causa es el apoyo de la casa, porque en la escuela se trabaja con el niño unas cuantas horas, pero sin el apoyo y refuerzo del hogar no va a salir adelante.

- $\quad$ (...) Un niño que no sabe leer no puede ir a segundo grado.

- Formación insuficiente de algunos docentes y poco compromiso con la labor educativa.

En síntesis, el soporte familiar se considera tan importante que se llega a afirmar lo siguiente: (...) la educación es compartida, 50\% los padres y $50 \%$ la escuela, hay que unirse para poder sacarlos adelante.

\section{Retos de la escuela ante el fracaso escolar}

Las escuelas de atención prioritaria cuentan con el apoyo de profesionales en Educación Especial y con un equipo interdisciplinario para atender integralmente a los escolares que lo requieran. No obstante, todos los informantes coincidieron en que dadas las características comunales, institucionales y personales, estos apoyos resultan insuficientes; razón por la cual 
algunos escolares no logran esa atención, pese a que son referidos por las docentes de aula.

Adicionalmente, la mayor parte de las escuelas de atención prioritaria cuentan con el servicio de PRIN. Sin embargo, se recomienda su ampliación y reestructuración, de tal forma que atienda solamente a los escolares que evidencian problemas en lectura, escritura y matemáticas. Esta recomendación obedece al hecho de que en algunos casos ese espacio se toma para hacer tareas, trabajos extraclase o estudiar para los exámenes; actividades estas que con una adecuada inducción puede realizarlas el niño de forma autónoma y así maximizar los recursos ofrecidos por el Ministerio de Educación.

Por otra parte, los directores manifiestan gran complacencia por el trabajo realizado por los docentes de Educación Especial y el equipo interdisciplinario. Es usual que estos profesionales sean quienes planteen proyectos especiales para recuperar a los niños con dificultades de lectura y escritura, tal es el caso de la Escuela Central de San Sebastián, institución que realiza proyectos específicos de lectura y escritura para niños con dificultades.

Puntualmente el fracaso escolar se trata de contrarrestar mediante la activación de las siguientes iniciativas:

- Recargos de PRIN para ofrecer recuperación.

- Equipo de Educación Especial e Interdisciplinario. En algunas escuelas se cuenta con códigos adicionales de maestros especiales: problemas de aprendizaje, problemas emocionales, terapia del lenguaje, aula recurso; no obstante, no es suficiente para atender las demandas de la población estudiantil.

- Iniciativas individuales de docentes: algunos docentes permanecen en la institución, fuera de horario, para brindar atención individualizada a niños con dificultades en el aprendizaje.

- Talleres a los padres de familia, pero penosamente asisten aquellos que menos necesitan reforzar sus responsabilidades para con los niños y la escuela.

Una de las tareas pendientes y, por tanto, que urge atender es la identificación de los niños con potenciales problemas de lectura, pero al iniciar el curso lectivo, a fin de implementar un programa institucional cuyo norte sea atender específicamente esas dificultades.

Por otra parte, en opinión de los directores también es necesario considerar lo siguiente:

- Brindar apoyo adicional a los niños con problemas de lectura y escritura como parte de la rutina de las aulas y en los servicios de apoyo.

- Maximizar la supervisión de la dirección, a fin de que el maestro identifique cuáles son los niños con dificultades, con el propósito de que institucionalmente se tomen medidas para "ayudar" de manera intensa a esos escolares en sus procesos de lectura y escritura.

En este sentido es fundamental dar mayor énfasis a los tópicos fundamentales en primer grado: los procesos iniciales de lectoescritura y matemáticas. Si la escuela da un énfasis especial a la lectura y la escritura, los contenidos de Estudios Sociales y Ciencias se integrarían como temáticas asociadas con los procesos de lectura y escritura. Dicho de otra manera, los niños leerán sobre los temas considerados en los programas de Estudios Sociales y Ciencias. Además, los procesos de expresión oral se enriquecerían con la discusión de esas temáticas y se fortalecerían los respectivos períodos de atención y escucha.

De forma recurrente los educadores han señalado que "la base para que se desarrollen las demás materias es que los niños lean y escriban". Por tanto, resulta ilógico que se diluya el esfuerzo en primer grado, que se evalúe sobre contenidos de las asignaturas básicas, cuando el niño apenas está iniciando el proceso de aprendizaje de la lectura y la escritura, tarea central de este grado.

Otra de las prácticas que debería ser modificada es la evaluación. En este sentido es necesario hacer efectivo el tránsito de una evaluación final y sumativa a una de proceso, en 
la cual el trabajo de aula sea el que sobresalga, respecto de las tareas, los trabajos extraclase y los exámenes. Esta recomendación obedece al hecho de que la escuela, con el modelo actual de evaluación, traslada un porcentaje sustantivo de sus responsabilidades a la familia como contraparte del proceso educativo. Si bien el apoyo familiar forma parte de un modelo ideal de educación compartida, la situación que se vive en las aulas refleja otra realidad. Por consiguiente, el trabajo complementario fuera de la escuela debe ser aquel que el niño pueda realizar de forma autónoma y es difícil valorarlo con porcentajes, por lo menos durante el período en el cual el niño está aprendiendo a leer y escribir, herramienta básica para iniciar el estudio y repaso independientes.

Por otra parte, estas modificaciones deben venir acompañadas con un período de adaptación que le permita al niño acomodarse y tomar gusto por las nuevas tareas escolares. Igualmente, es recurrente la demanda de docentes innovadores, creativos, observadores y flexibles, todo ello en pro de un proceso educativo más apegado a las características evolutivas, sociales, afectivas y cognitivas de los niños.

El hacer las cosas agradables, el priorizar al tenor de las necesidades y características específicas de los grupos son requerimientos de un primer grado exitoso.
Otro de los aspectos por considerar es analizar de manera integral los programas de las cuatro asignaturas básicas, los cuales se deben desarrollar a lo largo del año, junto con los procesos iniciales de lectura y escritura, los que, dada su naturaleza, requieren muchísimo tiempo y dedicación. En este análisis no debe obviarse que muchos niños costarricenses son tratados con inequidad, iniciando porque las escuelas de tercera jornada reducen el día escolar a tres horas y media, respecto de las de horario regular con cinco horas y las de jornada ampliada con siete. ¡Entonces, el tiempo dedicado a los procesos educativos es distinto!

Finalmente, con pesar los administradores de las escuelas señalan que: “los programas están tan cargados de tantas cosas que se dejan de lado la lectura y la escritura. Pero hay que cumplir con lo establecido".

\section{Retrato del niño que fracasa en primer grado}

En este apartado se describirá al escolar que fracasa al incumplir las demandas escolares, en virtud de una causación múltiple: un nivel de entrada que no se ajusta al perfil ideal, unas características familiares desventajosas, ambientes externos poco estimulantes, prácticas educativas que desconocen su realidad y su estilo de aprendizaje.

\section{DIRECTORES}

1. Niño que ingresa con bases insuficientes del kínder.

2. Niño con serios problemas de conducta y aprendizaje.

3. Niño con problemas de adaptación al ambiente escolar.

4. Niño proveniente de familias que no brindan apoyo a los procesos educativos que realiza la escuela.

5. Niño que aprende de manera diferente a la media, por tanto necesita más apoyo específico para que no quede rezagado respecto del grupo.

6. Niño con alto nivel de ausentismo.

\section{DOCENTES}

1. Niños con dificultades específicas de conducta.

2. Niños carentes de límites y normas básicas de convivencia.

3. Niños con problemas de adaptación al entorno escolar. No quieren escribir, prefieren dibujar y su período de atención es mínimo.

4. Niños con problemas varios de lenguaje: pronunciación defectuosa, vocabulario pobre, hablante de otra variedad de español, comprensión limitada,

5. Niños con conductas agresivas, muchas veces como respuesta a las dificultades de aprendizaje.

6. Niños provenientes de ambientes familiares poco estimulante y desinteresados por la escuela.

7. Niños que carecen de acompañamiento efectivo en el hogar, por tanto no cumplen con los trabajos extraclase y las tareas.

8. Niños que no muestran interés por los procesos de lectura y escritura ni por las otras tareas escolares.

9. Niños inmaduros, que debieron haber repetido el preescolar como medida preventiva.

10. Como contraparte también fracasan algunos niños excesivamente "sobreprotegidos". 
Niños portadores de todas o algunas de las características señaladas representan los porcentajes de reprobación, repitencia, deserción y sobreedad en el sistema educativo costarricense. Llama la atención la presencia de tres indicadores recurrentes en investigaciones realizadas dentro y fuera del país, a saber: el entorno familiar, la escuela y las características personales del educando. Esta caracterización es potencialmente útil al planificar el proceso educativo de esos niños, en el cual deben valorarse sus experiencias previas, descubrir cuál es su forma de aprender, identificar cuándo estará listo para iniciar el proceso de lectura y escritura convencionales, qué tipo de acompañamiento requiere al adaptarse al nuevo entorno educativo, qué aspectos del desarrollo de su lenguaje son más deficitarios. En consecuencia, estos niños deberían iniciar un proceso distinto, respecto de la colectividad que se ve identificada con el perfil ideal de un niño de primer grado. En este mismo sentido, la educación preescolar tendrá que focalizar su atención en las áreas débiles de ese niño, quien requiere de un claro proceso educativo compensatorio.

Por otra parte, los indicadores descritos en la tabla anterior resultan insuficientes si no se contemplan también los comportamientos positivos que esos niños manifiestan; por tanto, se motivó al docente para que describiera a un ex-alumno reprobado en primer grado en los últimos cinco años, incluyendo en esa caracterización aspectos positivos y negativos en la interacción comunicativa con ese niño, dificultades específicas manifiestas y razón fundamental por la que reprobó. A continuación se sintetizan las respuestas obtenidas.

TABLA 3

Caracterización de aspectos positivos y negativos del niño que fracasa en lectura y escritura

\begin{tabular}{|c|c|c|c|}
\hline $\begin{array}{l}\text { Aspectos positivos en la } \\
\text { interacción con el niño }\end{array}$ & $\begin{array}{l}\text { Aspectos negativos en la } \\
\text { interacción con el niño }\end{array}$ & Dificultades escolares & ¿Por qué reprobó ese niño? \\
\hline $\begin{array}{l}\text { Niña afectuosa y a la vez } \\
\text { carente de afecto. } \\
\text { Colaboradora en los } \\
\text { aspectos logísticos del } \\
\text { aula. }\end{array}$ & $\begin{array}{l}\text { Gustaba de llamar la } \\
\text { atención. }\end{array}$ & $\begin{array}{l}\text { Problemas de lenguaje } \\
\text { oral. } \\
\text { Problemas en el área de } \\
\text { motora fina, por ejemplo } \\
\text { no sabía recortar. }\end{array}$ & $\begin{array}{l}\text { Porque no aprendió a leer ni a } \\
\text { escribir. }\end{array}$ \\
\hline $\begin{array}{l}\text { Niño afectuoso con el } \\
\text { docente. } \\
\text { Le gustan los cuentos, las } \\
\text { películas, etc. }\end{array}$ & $\begin{array}{l}\text { Violento y agresivo con } \\
\text { los compañeros. } \\
\text { Niño muy territorial: } \\
\text { si alguien le quitaba su } \\
\text { lápiz o su espacio, lo } \\
\text { tomaba como amenaza } \\
\text { e inmediatamente se } \\
\text { defendía atacando } \\
\text { físicamente. }\end{array}$ & $\begin{array}{l}\text { Dificultades en el } \\
\text { aprendizaje de la } \\
\text { lectura y la escritura, } \\
\text { específicamente el } \\
\text { reconocimiento de } \\
\text { vocales y sílabas. } \\
\text { Además, era muy lento } \\
\text { al seguir instrucciones, } \\
\text { "era necesario repetirle } \\
\text { varias veces para que } \\
\text { entendiera". }\end{array}$ & $\begin{array}{l}\text { Por los problemas de } \\
\text { aprendizaje que presentaba, de } \\
\text { concentración, seguimientode } \\
\text { instrucciones. Además tenía } \\
\text { una forma particular de tomar el } \\
\text { lápiz, la cual hasta el momento } \\
\text { no se le ha podido corregir. }\end{array}$ \\
\hline Niño servicial. & $\begin{array}{l}\text { Niño tosco al jugar, } \\
\text { golpeaba y empujaba a los } \\
\text { compañeros. }\end{array}$ & $\begin{array}{l}\text { Dificultades en el } \\
\text { aprendizaje de la lectura } \\
\text { y la escritura. }\end{array}$ & $\begin{array}{l}\text { Por la lectoescritura en sí, avanzó } \\
\text { muy poco en el conocimiento de } \\
\text { las sílabas directas. }\end{array}$ \\
\hline
\end{tabular}




\begin{tabular}{|c|c|c|c|}
\hline $\begin{array}{l}\text { Niña extrovertida y } \\
\text { servicial. }\end{array}$ & $\begin{array}{l}\text { Se rendía muy fácilmente, } \\
\text { carecía de la capacidad de } \\
\text { persistencia. }\end{array}$ & $\begin{array}{l}\text { Dificultades en el } \\
\text { aprendizaje de la lectura } \\
\text { y la escritura }\end{array}$ & $\begin{array}{l}\text { Por la lectoescritura en sí, avanzó } \\
\text { muy poco en el conocimiento de } \\
\text { las sílabas directas. }\end{array}$ \\
\hline $\begin{array}{l}\text { Niño colaborador y } \\
\text { servicial. Gustaba mucho } \\
\text { de ayudar a mantener } \\
\text { limpia el aula. } \\
\text { Mostraba una buena } \\
\text { relación cordial con los } \\
\text { compañeros y maestro. }\end{array}$ & $\begin{array}{l}\text { Provocaba desorden en el } \\
\text { aula y molestaba a los } \\
\text { compañeros mientras } \\
\text { estos trabajaban. } \\
\text { Presentaba conductas } \\
\text { agresivas. Presentaba } \\
\text { conductas agresivas. }\end{array}$ & $\begin{array}{l}\text { Dificultades en el } \\
\text { aprendizaje de la lectura } \\
\text { y la escritura. Le fue } \\
\text { muy difícil formar y } \\
\text { comprender oraciones. } \\
\text { Dificultades en el } \\
\text { aprendizaje de la lectura } \\
\text { y la escritura }\end{array}$ & $\begin{array}{l}\text { Porque no logró aprender a leer } \\
\text { ni a escribir con ningún método. } \\
\text { Era un niño muy inmaduro. } \\
\text { Por el tipo de evaluación que se } \\
\text { sigue en la escuela, pues no se da } \\
\text { oportunidad al niño de avanzar a } \\
\text { su propio ritmo. }\end{array}$ \\
\hline $\begin{array}{l}\text { Niño que gustaba de jugar } \\
\text { y asistir a la escuela. }\end{array}$ & $\begin{array}{l}\text { Manifestaba ausencia de } \\
\text { límites. } \\
\text { No mostraba interés } \\
\text { por aprender a leer y a } \\
\text { escribir. } \\
\text { Provenía de un ambiente } \\
\text { familiar no estimulante. }\end{array}$ & $\begin{array}{l}\text { Dificultades en el } \\
\text { aprendizaje de la lectura } \\
\text { y la escritura }\end{array}$ & $\begin{array}{l}\text { Por ausentismo y, en } \\
\text { consecuencia, no logró el mínimo } \\
\text { deseado en lectoescritura. }\end{array}$ \\
\hline
\end{tabular}

Cuando se visualiza a un niño proveniente de un ambiente poco estimulante, con evidentes dificultades de aprendizaje, con comportamientos agresivos, etc., es casi imposible pensar que de entre ese cúmulo de "circunstancias o conductas poco prometedoras" aparezca algo positivo. Identificar aspectos positivos en esas conductas quizá sea un primer paso al iniciar procesos de intervención pedagógica humanos y oportunos.

Estos niños llegan a la escuela con serias debilidades en el área emocional y con carencias familiares que interfieren en la activación de los procesos cognitivos necesarios para leer y escribir. No obstante, son niños serviciales y colaboradores, dos rasgos de personalidad que colocados en terreno fértil pueden impulsar el fortalecimiento de las debilidades identificadas.

Del área cognitiva cabe recalcar el impacto de la poca estimulación del lenguaje y su incidencia directa en los procesos iniciales de lectura. Uno de los aspectos que recalcan los docentes es el déficit en el seguimiento de instrucciones y las dificultades en la expresión oral.

En consecuencia, esos aspectos deben trabajarse desde la educación preescolar y continuar en primer grado; de lo contrario poco podría lograrse al iniciar directamente la enseñanza de la lectura y la escritura. La escucha atencional, el seguimiento de instrucciones, el enriquecimiento del vocabulario, motivación a la lectura, el enriquecimiento de los procesos de comprensión mediante la exposición a experiencias variadas y el inicio de los procesos de lectoescritura, serán objetivos básicos en primer grado.

Por otra parte, se indagó acerca del tipo de apoyo educativo o atención particular que reciben estos niños; al respecto los educadores centran su esperanza en los servicios de apoyo escolar, los cuales, lamentablemente, son insuficientes para atender todas las demandas escolares. Veamos uno de los testimonios:

"Bueno, es difícil ayudar a un niño que viene entrando a su primer grado, dado que es una escuela con más de 2000 estudiantes, una escuela que está en completo hacinamiento, muy olvidada por el MEP. Lamentablemente se cuenta únicamente con los apoyos básicos de educación especial, pero no dan abasto, las listas de espera son de más de 100 estudiantes, por lo que en un año no logran abarcar todas las necesidades de la institución. El niño estuvo en PRIN y fue atendido por la psicóloga. El problema es que el PRIN se da en el pasillo, donde hay muchos distractores y el niño no logra concentrarse, por lo que el avance es mínimo" (Docente de primer grado, entrevista efectuada el lunes 3 de octubre de 2011).

En general las docentes recurren al equipo interdisciplinario y al de Educación Especial, en caso de contar con estos servicios. Algunas 
veces se intenta ayudar al niño incorporando en la rutina diaria actividades que respondan a sus necesidades, por ejemplo los "círculos de armonía", estrategia de exteriorización de deseos, sentimientos y opiniones que fue aplicada por una docente entrevistada, a fin de minimizar las conductas agresivas y poco asertivas de estos escolares.

Por otra parte, las docentes insisten en señalar como responsables primarios a los grupos familiares de los niños, quienes no apoyan la labor de aula; incluso se afirma con molestia que la institución "no es una guardería" y con vehemencia se interrogan: "¿qué es lo que los papás piensan?", a manera de reproche por la falta colaboración.

Consideramos que la situación particular de estos niños debe atenderse de manera integral, pues no basta con culpabilizar a las familias, a las comunidades, a las carencias individuales; por el contrario, es urgente mirar hacia adentro y preguntarnos cuáles son los factores escolares, metodológicos, éticos, etc. que están favoreciendo el fracaso de un grupo de niños costarricenses.

Por otra parte, las voces de descontento y los lamentos por el desamparo que siente el docente irremediablemente afectan su desempeño profesional $\mathrm{y}$, por consiguiente, es impostergable atender al maestro con la misma prontitud con que debe atenderse a los niños con dificultades escolares. Dicho de otra manera, los docentes requieren de un soporte emocional que les permita valorar las oportunidades de sus ambientes laborales y minimizar las debilidades a fin de tornar más agradable su ejercicio profesional.

Otra de las variables consideradas al indagar sobre el tema objeto de estudio, fue la relación tiempo y procesos de aprendizaje. Si bien teóricamente se señala que el rango de tiempo para aprender a leer y a escribir sobrepasa un año escolar, las docentes entrevistadas afirman que la estructura de los programas actualesprimero y segundo grado- condiciona el patrón seguido al aprobar o reprobar a un niño de primer grado. En Costa Rica el niño debe aprender a leer y a escribir en primer grado, pues en segundo se hacen otras cosas. Atendamos la siguiente opinión puntual:
"Estamos hablando de niños que aprenden normalmente pero que requieren nivelarse en segundo grado, el problema es que el programa de segundo grado no me permite a mí reforzar la lectoescritura, no está en el programa. O sea, se hace, pero no está en el programa. Por ejemplo, el inicio en segundo grado debe iniciarse con sílabas mixtas y con temas de las otras materias; imagínese un niño que aún no ha alcanzado los niveles esperados en lectura y escritura. Es muy contradictorio. Por otro lado, hay una cosa que las maestras de primaria criticamos mucho y es todo el tiempo que se le dedica al apresto y eso es algo que le corresponde al preescolar; entonces es un tiempo que podríamos aprovechar para reforzar la lectura" (Docente de educación primaria, entrevista realizada el miércoles 5 de octubre de 2012).

De acuerdo con ese comentario, el docente responde a un programa predefinido y obvia categóricamente el proceso de desarrollo del niño, sus conocimientos previos, intereses, necesidades, no conceptualiza el aprendizaje como un continuum, etc.; así las cosas, los niños deben ajustarse al programa y no el programa a los niños, ensanchando las cifras de fracaso escolar. Dicho de otra manera, lo que no está en el programa no se hace, no es permitido, no existe, a pesar de que la situación particular de un niño requiera algunas adecuaciones para atender sus necesidades particulares.

Los docentes entrevistados reconocen que los niños que fracasan en lectura y escritura muestran estilos distintos de aprendizaje (actividades muy cortas y variadas, mayor refuerzo visual, alternar entre espacios de reposo y de movimiento, etc.), por lo que la enseñanza debería ser también distinta. Estos escolares requieren una motivación adicional, pero la jornada escolar es insuficiente para atender las diferencias individuales, los grupos son muy numerosos (una de las docentes participantes tuvo en el 2010 un grupo de primer grado con 45 niños); además, los requerimientos programáticos de las asignaturas básicas ahogan el quehacer escolar, y, en consecuencia, se resta tiempo a la exploración, al juego, al movimiento, a la expresión oral y a la estimulación integral del niño. Una vez más la intervención didáctica 
oportuna y apegada a los características de los niños se ve supeditada a las demandas de una estructura verticalista que desconoce el quehacer del aula.

En adición, una de las docentes afirma que estos niños requieren una atención individual de casi un 100\%; los aprendizajes son mayores si se les motiva, se fortalece la modalidad visual, se recurre a material concreto y vivencial. Una experiencia exitosa para esta docente es asignar un compañero tutor que guíe, facilite y acompañe los procesos de aprendizaje de estos escolares.

$\mathrm{Si}$ bien los aspectos diferenciadores en la intervención pedagógica son fundamentales al trabajar con estos niños, los patrones de comportamiento, los hábitos de aseo y de orden, las actitudes positivas hacia el aprendizaje deben constituirse también en objetivos didácticos prioritarios en primer grado.

Uno de los aspectos que sobresalen en las intervenciones docentes es la necesidad de poner en práctica métodos de enseñanza de la lectura diferenciados, según las necesidades de los niños. Al respecto una maestra señaló que "hizo una combinación del método silábico con el ecléctico, este sistema resulta y funciona en los sistemas de atención prioritaria, pues no requiere mucho apoyo de los padres y permite alcanzar mayor fluidez en la lectura. Es necesario buscar entonces el método que funcione para la realidad en la cual se está y al tipo de niños que se tienen".

En síntesis, es vital revisar, al menos, los programas de primero y segundo grado, niveles cuya meta es que el niño aprenda a leer y a escribir.

\section{Hacia el éxito en primer grado}

De acuerdo con el criterio de los directores de las instituciones escolares investigadas, un primer grado que asegure el éxito escolar es aquel que vive un proceso de lectoescritura adecuado, o sea, en el cual los niños estén interesados en la lectura, la escritura, ávidos de escuchar cuentos, de conocer los números y de jugar.

El docente es quizá la pieza fundamental, pues su formación unida a la disposición, interés y gusto por enseñar a leer y a escribir marcará la diferencia entre un grupo y otro. Otra condición que no debe obviarse es el tamaño del grupo; cuanto menor sea el grupo de estudiantes habrá mayores posibilidades de ofrecer una educación más acorde a las diferencias individuales y, por tanto, más respetuosa del niño y sus derechos.

Igualmente, hay conceso al considerar el primer grado como la clave del éxito en la historia escolar del niño; iniciar los procesos de lectura y escritura de una manera agradable, sin la atadura de un examen, el cual no mide verdaderamente la capacidad del niño y el proceso que está viviendo, el trabajo fuerte con hábitos de orden, de aseo, la responsabilidad, etc., son los tópicos básicos del primer año escolar.

Un primer grado exitoso requiere como mínimo lo siguiente:

- Mejorar el perfil docente: profesional comprometido con su trabajo, espíritu creativo y con grandes deseos de superación.

- $\quad$ Elaborar un proyecto educativo adecuado a las necesidades comunales e institucionales.

- Hacer efectiva la inclusión de las familias en el proceso educativo.

- Crear una red de apoyo institucional que ofrezca acompañamiento a los docentes y las familias de niños con problemas específicos de lectura y escritura.

- Contar con un docente itinerante que ofrezca apoyo a los diferentes grupos de primer grado durante el horario regular.

- Modificar la evaluación, de tal forma que visualice como un proceso.

- Crear la figura del maestro asistente en primer grado, a fin de hacer efectiva la atención individualizada de los niños.

\section{Sintesis de resultados}

En términos generales, las causas del fracaso escolar se analizan desde tres perspectivas: las pautas pedagógicas e institucionales, o sea causas internas; la familia y el contexto extraescolar, causas externas, y el niño, causas personales. Por tanto, a partir de esa forma de clasificar las múltiples causas que intervienen en este fenómeno socioeducativo se presentan a continuación las principales causas y se ofrecen recomendaciones y estrategias aportadas por los participantes en este estudio. 
TABLA 4

Cuadro resumen

\begin{tabular}{ccc}
\hline Causas del fracaso escolar & Recomendación & Estrategia \\
\hline & Causas Internas & \\
\hline
\end{tabular}

1. Planificación curricular orientada 1. Integración curricular. Los hacia el aprendizaje de contenidos desarticulados.

contenidos curriculares de Ciencias y

Estudios Sociales se integrarán como temáticas específicas para enriquecer el bagaje cultural del alumno y favorecer los procesos de comprensión lectora, expresión oral, escucha comprensiva y atencional.

2. Prácticas docentes orientadas hacia la colectividad.

2. Proponer métodos de lectoescritura inicial multisensoriales y dirigir la atención hacia la creación de las condiciones necesarias para que el niño aprenda de una forma natural, mediante la experimentación con los textos, las palabras, las sílabas y los fonemas.

3. Invisibilidad organizacional de los niños repitentes y con dificultades de lectura y escritura.

4. Imprecisión en la valoración del tiempo y dedicación que requieren los procesos iniciales de lectura y escritura.

3. Creación de un programa de seguimiento a los niños repitentes y con dificultades de lectura.

4. Ajustar el período del aprendizaje de lectura y escritura al desarrollo del niño y a la realidad de las jornadas escolares (jornada regular, ampliada y tercera jornada).
5. Programas actuales del área de lengua y sistema de evaluación condicionan el patrón seguido al aprobar o reprobar a un niño.

5.1 Reestructurar el sistema de evaluación vigente, de tal forma que sea efectivo el paso de una evaluación de productos, a una que valore los procesos de aprendizaje del alumno. 5.2 Revisar los criterios de aprobación o reprobación en primer grado.

6. Docentes sin formación 6. El docente de primer ciclo de la especializada en procesos de educación básica debe especializarse en enseñanza y aprendizaje de la lectura los procesos de enseñanza y aprendizaje y la escritura. de los niños de seis a diez años y poseer experticia en la enseñanza de la lectura y la escritura.

7. Desfase entre el perfil de salida del nivel de transición y el perfil de entrada de primer grado

7. Ofrecer una intervención pedagógica intencionada en el nivel de transición, que desencadene en el gusto por la
1.1 Definir prioridades educativas por grado.

1.2 Asumir como eje orientador del primer ciclo las competencias de lectura y escritura.

2. Creación de las condiciones idóneas para el aprendizaje de la lectura y la escritura, según las características particulares de cada grupo. Posibilitar el uso de metodologías de enseñanza diferenciadas según las particularidades de los niños.

3. Ofrecer un programa que atienda las necesidades de los niños repitentes con dificultades de lectura y escritura.

4. Tomar como ejes básicos para primero, segundo y tercer grados los procesos de lectura y escritura.

5.1 Implementar un sistema de evaluación por criterios que responda al proceso de desarrollo y adquisición de conocimientos de los niños.

5.2 Promoción automática de primero a segundo grado.

6. Organizar programas de formación continua centrados en los procesos de aprendizaje de le lectura y la escritura. lectura y la escritura funcionales, la escritura y lectura del nombre propio, el conocimiento de las vocales, el enriquecimiento lingüístico en general y el desarrollo de la conciencia fonológica, todos aspectos básicos para el futuro éxito en la lectura y la escritura.
7.1 Facilitar espacios de diálogo constructivo entre docentes de preescolar, primaria, planificadores curriculares y especialistas en desarrollo del niño, torno al niño costarricense de hoy, sus necesidades de desarrollo y los retos que afrontará en el sistema educativo a partir de primer grado.

7.2 Organización de un programa de enriquecimiento de las competencias lingüístico comunicativas de los niños desde preescolar hasta tercer grado. con el propósito de que reflexionen en 


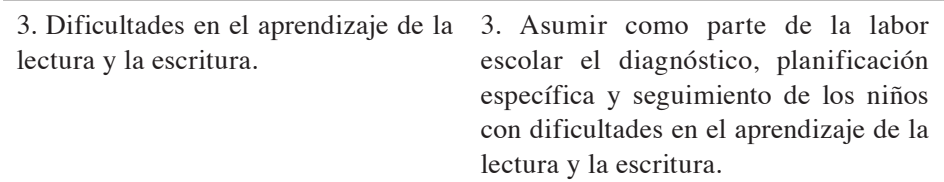

3. Redefinir las competencias del PRIN, con el fin de que se atienda de forma sistemática a los niños con dificultades en el aprendizaje de la lectura y la escritura.

\section{Causas Externas}

1. Situación familiar:

1. Maximizar el modelaje de la institución educativa hacia formas de vida saludables, la valorización de la educación como instrumento de movilización social, otorgar a los procesos de lectura y escritura mayor espacio como medio de aprendizaje y de desarrollo humano. En este sentido se opta por una escuela autosuficiente, que resuelva todas sus necesidades dentro de la escuela, sin considerar a la familia como contraparte educativo.

1.1 El apoyo familiar forma parte de un modelo ideal de educación compartida, pero la situación que se vive en las aulas refleja otra realidad. Por consiguiente, el trabajo complementario fuera de la escuela debe ser aquel que el niño pueda realizar de forma autónoma.

1.2 Reconceptualizar el "trabajo extraclase", de modo se asignen solamente responsabilidades que el niño pueda realizar de forma autónoma y considerando su contexto familiar y posibilidades económicas.

2. Expectativas familiares. 2. Crear instancias educativas para Permanencia en la escuela; alfabetizar a los padres de familia o a rendimiento académico; educación los cuidadores de los niños que no leen como mecanismo de ascenso social. ni escriben. Esta medida contribuiría a que las familias valoren la institución educativa y la vivencien con sus hijos.

3. Déficits ambientales. 3. Crear un programa de lenguaje que abarque los niveles de preescolar a tercer grado, cuya meta sea ampliar la competencia lingüístico-comunicativa de los niños.
2. Ampliar el sistema de educación abierta para atender a las familias que no saben leer y escribir en el mismo horario, que sus hijos asisten a la escuela.

3. Modificar la organización escolar, con el propósito de que preescolar y primer grado pertenezcan al mismo ciclo escolar. Esto con el fin de que sea el mismo docente quien asuma el proceso de transición e iniciación de la lectura y escritura convencionales.

Causas Personales

1. Niños que presentan problemas en el desarrollo del lenguaje: vocabulario

1.1 Revisión de las responsabilidades de la educación preescolar y su rol en la estimulación del desarrollo del niño, en particular el lenguaje, el conocimiento del esquema corporal y la lectoescritura emergente.

1.2 Diseño de programas paralelos para nivelar a los niños que ingresan al primer grado sin los conocimientos previos necesarios para iniciar un proceso de lectoescritura convencional.

2. Ausentismo

2. Creación de programas específicos de seguimiento a los niños con altos porcentajes de ausentismo.
1.1 Focalizar la atención en las áreas débiles de los niños, de tal forma que quien requiera en una educación compensatoria la reciba.

2. Crear mecanismos de información sobre la obligatoriedad de asistir a la escuela y especificar las consecuencias legales del incumplimiento de esta disposición. 


\section{A manera de conclusión}

Las principales causas del fracaso escolar identificadas por los participantes en este estudio se sitúan en el ámbito pedagógico, institucional y organizacional. Los niños que reprueban en lectura y escritura presentan dificultades de aprendizaje, poseen carencias producto de ambientes poco enriquecedores, $\mathrm{y}$, en consecuencia, presentan períodos muy cortos de concentración, pobreza de vocabulario, dificultades en la motora fina y gruesa, no logran aprender con el método de lectura que utiliza el docente, muestran inseguridad, dificultades en el seguimiento de instrucciones e insuficientes límites para seguir las normas de convivencia en el aula. Estos niños, en general, requieren de una atención individualizada, con la cual tendrían muchas posibilidades de seguir adelante con los requerimientos escolares.

Por otra parte, los docentes reconocen que en casi todo grupo de primer grado hay niños que presentan dificultades al aprender a leer y a escribir; pero el verdadero problema radica en la poca pericia del docente para atender oportunamente las diferencias individuales; aspecto que debe trabajarse desde la formación universitaria y atenderse en los procesos de capacitación que ofrece el Ministerio de Educación Pública.

En fin, la gran pregunta que debe plantearse el docente es: ¿cómo aprenden a leer y a escribir los niños que tienen dificultades de aprendizaje?, pues aquellos que no los tienen aprenden rápidamente y de cualquier forma, siempre y cuando se hayan creado las condiciones necesarias para esos aprendizajes.

\section{Nota}

1. El Programa de Recuperación Integral de los Niños -PRIN- es un servicio de apoyo escolar, que consiste en la atención individual por un periodo de dos lecciones semanales, a los niños con dificultades y que han sido referidos previamente por sus maestros regulares.

\section{Bibliografía}

Acosta, Gladys. 2007. Presentación de la colección Todos Pueden Aprender. Buenos Aires: UNICEF.

Blakemore, Sarah-Jayne. y Frith, Uta. 2006. Cómo aprende el cerebro. Las claves para la Educación. Barcelona: Ariel S.A.

Blat, José. 1984. El fracaso escolar en la enseñanza primaria: medios para combatirlo. Organización de las Naciones Unidas para la Educación, la Ciencia y la Cultura. Ginebra: ATAR S.A.

Binstock, Georgina. y Cerutti, Marcela. 2005. Carreras truncadas. El abandono escolar en el nivel medio en la Argentina. Buenos Aires: UNICEF.

Cardoso-Martins, Claudia. Lefly, Dianne. y Pennington, Bruce. 2001. Comparing the phonological and double deficit hypotheses for developmental dyslexia. Reading and Writing: An Interdisciplinary Journal, 14, 707-755.

Castillo, Cristina. 2011. Comunidades de aprendizaje: una opción ante el fracaso escolar. Intersedes: Revista Electrónica de las Sedes Regionales de la Universidad de Costa Rica, XII (23), 74 - 102.

Chall, Jeanne. 1967. Learning to read: The great debate. New York: McGraw-Hill.

Choque, Raúl. 2009. Ecosistema educativo y fracaso escolar. Revista Iberoamericana de Educación, 49 (4), 1 - 9.

Coltheart, Max. 1985. Cognitive neuropsychology and the study of reading. En Michael Posner y Oscar S. M. Marin (Eds.), Attention and performance XI, 3-37. 
Coltheart, Max, Curtis, Brent, Atkins, Paul, y Haller, Micheal. 1993. Models of reading aloud: Dual-route and parallel distributed processing approaches. Psychological Review.

Ellis, Andrew. 1985. The cognitive neuropsychology of developmental (and acquired) dyslexia: A critical survey. Cognitive Neuropsychology, 2, 169-205.

Escobedo, Paula. 2010. El aprendizaje de la lectura y la escritura desde las prácticas docentes. Jornades de Foment de la Investigación. Castellón: Universitat Jaume I.

Farías, Mónica, Fiol, Dolores, Kit, Irene y Melgar, Sara. 2007. Propuestas para superar el fracaso escolar. Buenos Aires: UNICEF.

Fernig, Leo. 1972. Fracaso escolar y origen social de los alumnos. El Correo, 5, 4-6.

Fons, Montserrat y Buisán, Carmen. 2010. La Detección de las prácticas docentes para enseñar a leer y a escribir. Congrés Internacional de Didàctiques 2010. Girona: Universitat de Girona.

León, Ana Teresa. 2010. Principales razones del fracaso escolar en primer grado en Costa Rica. III Estado de la Educación. San José: Consejo Nacional de Rectores.

León, Ana Teresa. 2011. Las relaciones interpersonales en la transición de los estudiantes de la primaria a la secundaria. Revista Electrónica Educare, XV(1) 193-210.

López, Néstor y Gluz, Nora. 2002. Estrategias sistémicas de atención a la deserción, la repitencia y la sobreedad en escuelas de contextos desfavorecidos. Buenos Aires: OEA/MECT.
Ministerio de Educación Pública de Costa Rica. 1995. Programa de Estudio del Ciclo de Transición. Educación Preescolar. San José.

Morales, María Ester. y Salas, Natalia. 2002. Reflexiones en torno al fracaso escolar. Revista Educare, 2, 37 - 47.

Ortiz, Tomás. 2009. NeuroCiencia y Educación. Madrid: Alianza Editorial.

Passow, Harry. 1972. Diez causas principales de la desigualdad de oportunidades. El Correo, 5, 7 - 12 .

Patterson, Karalyn. y Morton, John. 1985. From orthography to phonology: An Attempt at an old interpretation. En Karalyn Patterson, John Marshall, y Max Coltheart (Eds.), Surface dyslexia: Cognitive and neuropsychological studies of phonological reading (335-360). Hove: Erlbaum.

Programa Estado de la Nación en Desarrollo Humano Sostenible. 2011. III Informe del Estado de la Educación. San José: Consejo Nacional de Rectores.

Puente, Aníbal. 2001. El viaje de las letras $y$ los problemas de lectura. Madrid: Biblioteca Nueva.

Ríos, Isabel, Fernández, Pilar y Gallardo, Isabel. 2010. La contribución de las prácticas de aula. A los logros de aprendizaje. Congrés Internacional de Didàctiques 2010'. Girona,: Universitat de Girona.

Torres, Rosa Marí. 2007. Todos pueden aprender. Conceptos para seguir trabajando en propuestas para superar el fracaso escolar. Buenos Aires: UNICEF. 